\title{
然 \\ APLICANDO O MODELO DE PRESIDENCIALISMO DE COALIZÃO AO MUNICÍPIO DE SÃO PAULO: PREDOMÍNIO DO EXECUTIVO OU MAIOR COMPARTILHAMENTO DE PODER?
}

\author{
APPLYING THE COALITION'S PRESIDENTIALISM MODEL TO THE CITY OF \\ SÃO PAULO: PREDOMINANCE OF THE EXECUTIVE OR GREATER SHARING OF \\ POWER?
}

\section{UTILIZANDO EL MODELO DE PRESIDENCIALISMO DE COALICIÓN EN LA MUNICIPALIDAD DE SAO PAULO: ¿PREDOMÍNIO DEL EJECUTIVO O MAYOR DISTRIBUCIÓN DE PODER?}

\author{
Akira Pinto Medeiros ${ }^{1}$ \\ Marcello Fragano Baird ${ }^{2}$ \\ Marcela dos Santos Camargo ${ }^{3}$
}

\begin{abstract}
Resumo: O artigo tem como objeto de estudo o padrão de interação entre Executivo e Legislativo na produção legal no Município de São Paulo entre a aprovação do atual Regimento Interno da Câmara Municipal de São Paulo (1991) e o término da legislatura encerrada em 2016. Busca-se observar se existem diferenças nesse padrão de interação na comparação com a esfera federal sob a égide do modelo de presidencialismo de coalizão. Utilizam-se dados de tramitação dos Projetos de Lei apresentados de acordo com seus proponentes para trabalhar com os conceitos de "dominância" e "sucesso" no âmbito municipal. Destacam-se alguns achados: I - A porcentagem de matérias apresentadas e promulgadas dentro de 4 anos é alta; II - A maioria das matérias apresentadas tem origem no Parlamento; III - Percebe-se um sucesso maior do Executivo frente ao Legislativo na aprovação de matérias, embora com taxas bem inferiores ao padrão federal; IV - As taxas de dominância do Executivo Municipal é baixa em comparação com o Executivo federal, o que sugere maior compartilhamento de poder com o Legislativo.
\end{abstract}

Palavra-chave: Processo Legislativo; São Paulo; Poder Legislativo Municipal; Poder Executivo de São Paulo; Câmara Municipal de São Paulo.

\footnotetext{
Abstract: This article has the objective to study patterns of interaction between the Executive and the Legislative branches of government, in the City of São Paulo, between the promulgation of the City Council bylaw (1991) and the legislative period ended in 2016. We seek to observe if there are pattern differences' between the municipal level and the Federal level through the usage of the coalition's presidentialism model. We use data from all laws presented according to its presenter to work with the concepts of "dominance" and "success" at the municipal level. The main findings are described as: I - the percentage

${ }^{1}$ Mestrando em Ciência Política pela Universidade de São Paulo (USP), Pós-graduado em "Legislativo e Democracia no Brasil" pela Escola do Parlamento da Câmara Municipal de São Paulo, e, Bacharel em Relações Internacionais pela Pontifícia Universidade Católica de São Paulo (PUC-SP). Orcid: https://orcid.org/0000-0003-2763-8824 E-mail: akira.pinto@gmail.com

${ }^{2}$ Graduado em Relações Internacionais pela Pontifícia Universidade Católica de São Paulo e em Ciências Sociais pela Universidade de São Paulo (USP), é mestre e doutor em Ciência Política pela USP. Professor do curso de Relações Internacionais da Escola Superior de Propaganda e Marketing e do MBA em Economia e Gestão: Relações Governamentais da Fundação Getúlio Vargas (FGV-IDE) em São Paulo.ORCID iD https://orcid.org/0000-00017675-7577 E-mail: marcellofb@ hotmail.com

${ }^{3}$ Mestranda em Administração Pública e Governo - FGV-EAESP. Bacharela em Economia pela FGV-EESP, e Pesquisadora no Instituto de Estudos para Políticas de Saúde (IEPS). Orcid; https://orcid.org/0000-0002-0120-238X E-mail marcela_camargo274@hotmail.com
} 
of laws presented and voted inside each legislature period is high; II - the majority of the laws presented came from the Legislative branch; III - The Executive branch has a greater success in its propositions even though this power underperforms what is seen at the Federal Level; IV - The Municipal Executive branch tax of dominance is low in comparison to the dominance presented by the Federal Executive, suggesting a greater share of power between powers in the Municipal level.

Keywords: Legislative Process; São Paulo; Municipal Legislative Branch; São Paulo’s Executive branch; São Paulo City Council.

Resumen: El artículo tiene como objetivo estudiar padrones de interación de los poderes Ejecutivo y Legislativo en la produción legal del Municipio de São Paulo entre la aprobación del regimento interno de la Camara de Consejales (1991) y el término de la legislatura terminada en 2016. Se proponen observar si hay diferencias en el padrón de interación de poderes con lo que se observa a nível federal atraves del modelo del presidencialismo de coalisión. Se usan datos del trámite de los proyectos de ley presentados por cada poder para trabajar con los conceptos de "dominanza" y "éxito" en la esfera municipal. Los principales resultados son: I - El percentaje de proyectos presentados y promulgados dentro de 4 años es alto; II - La mayoria de los proyectos presentados tienen origem en el la Camara de Consejales; III - Se nota un mayor suceso del Ejecutivo frente al Legislativo enl la aprobación de leyes, pero con tajas bién inferiores a lo que se verifica al nível federal; IV - Las tajas de dominancia del Ejecutivo Municipal son bajas en comparación con el Ejecutivo federal, lo que indica un mayor compartillamiento de poder com el Legislativo.

Palabras clave: Proceso Legislativo; São Paulo; Poder Legislativo Municipal; Poder Ejecutivo de São Paulo; Camara de Consejales de São Paulo;

\section{Introdução}

A maior parte dos estudos sobre relações Executivo e Legislativo feitos pela Ciência Política brasileira ateve-se à formação de maiorias para a coalizão da Presidência da República no Legislativo Federal, uma vez que o cerne da discussão relacionava-se ao embate entre sistemas políticos (Parlamentarista ou Presidencialista) e o regime democrático. A linhagem de estudos decorrente do trabalho de Figueiredo e Limongi (2001) aponta para a estabilidade da interação entre estes poderes através da análise da produção legislativa majoritariamente coordenada pela Presidência e da elevada taxa de sucesso desta instituição em suas proposições legislativas. Verificada a baixa ocorrência de estudos para o nível municipal com este enfoque e a quase inexistência de textos que analisem mais do que duas administrações do Executivo paulistano, julga-se importante analisar, de maneira específica, os resultados no Processo Legislativo Municipal das coalizões governamentais em um espaço de tempo estendido. Sendo São Paulo a capital com o maior número de vereadores do país, uma análise sobre as relações entre Executivo e Legislativo, por meio da produção legal nesta cidade, é particularmente importante. Diante do exposto, este artigo busca identificar indicativos da eficiência das administrações da Prefeitura de São Paulo (PMSP) entre 1991 e 2016 na execução da agenda parlamentar do Executivo por meio de cálculos sobre o sucesso e a dominância do Executivo no processo legislativo. As análises apresentadas neste trabalho procuram dialogar com os estudos anteriores a fim de permitir avanços na compreensão das relações entre poderes.

Busca-se, por meio das análises de dados das gestões compreendidas entre a promulgação da Lei Orgânica do Município (LOM) e do Regimento Interno da Câmara Municipal (RICM), e o fim de 2016, analisar de maneira ampla o desempenho do poder Executivo paulistano na 
produção legal do Município entre 1991 e 2016, inclusive comparando administrações.

O artigo está dividido em quatro partes. A primeira constitui uma revisão bibliográfica do tema e suas fundações teóricas. A segunda é constituída pela explanação da metodologia utilizada e da hipótese do trabalho, enquanto que a terceira parte é constituída pela análise de dados sobre o Processo Legislativo de São Paulo. O artigo se encerra com conclusões e apontamentos para o prosseguimento de estudos.

\section{Presidencialismo de coalizão: da esfera federal à municipal}

\subsection{O debate institucional brasileiro}

Este trabalho orienta-se pelos estudos a respeito do Sistema Político Brasileiro (SPB), especificamente aqueles que se preocuparam em compreender a relação entre os poderes Executivo e Legislativo federal após a promulgação da Constituição Federal de 1988 (CF88).

A literatura especializada que aborda as relações entre Executivo e Legislativo na cidade de São Paulo é pautada pelos estudos de nível Federal e indica a necessidade da formação de coalizões, a fim de possibilitar a obtenção da chamada governabilidade no sistema proporcional e multipartidário. Os primeiros estudos acerca da relação entre os dois poderes mencionados tiveram teor pessimista sobre o funcionamento do SPB. Explicações pautadas em uma suposta conexão entre a preferência por políticas públicas distributivas (emendas ao orçamento) e uma fragilidade dos partidos no parlamento e nas arenas eleitorais apontavam para uma inevitável paralisia decisória do sistema. Outro fator relevante nestas abordagens seria a existência de um padrão fisiológico de interação entre os poderes. O modelo fisiológico, segundo Abrucio e Couto (1995), encontra no sistema presidencialista um arcabouço que incentiva a obtenção de maioria parlamentar por parte do Executivo, garantindo a governabilidade necessária e ao mesmo tempo provocando, ocasionalmente, um "eclipsamento" do Legislativo pelo Executivo devido à falta de independência que aquele passaria a ter. Esta situação geraria um desequilíbrio com clara sobreposição do Executivo, haja vista a existência de uma interação fisiológica entre os interesses do Governo e os interesses individuais de cada parlamentar.

Abranches (1988) apresenta uma avaliação temerosa sobre o modelo presidencialista brasileiro, denominado pelo autor de presidencialismo de coalizão. Em sua visão, o Brasil vivia, na transição para a democracia, um dilema institucional oriundo da necessidade de optar por um modelo político suficientemente eficiente para agregar e processar pressões derivadas de um quadro social, econômico e político heterogêneo. Assim, a adoção de um modelo proporcional, multipartidário e presidencialista, no qual o Executivo é organizado com base em grandes coalizões, possuiria potencial de conflito muito alto e tornaria improvável a estabilidade de grandes coalizões em momentos de crise (ABRANCHES, 1988, p. 30).

$\mathrm{Na}$ contramão de Abranches, estudos que emergiram no início dos anos 2000 apresentaram dados indicando que o presidencialismo de coalizão no Brasil era estável e que o 
presidente da República possuía ferramentas que garantiam a governabilidade do sistema. Isso poderia ser mensurado pelas taxas de sucesso do presidente ao aprovar sua agenda legislativa e pela taxa de dominância do presidente em relação ao conjunto de leis aprovadas (FIGUEIREDO; LIMONGI, 2001) $)^{4}$. Esses autores identificaram, ao compararem as taxas de dominância e sucesso do Executivo em relação ao Legislativo no caso brasileiro com experiências internacionais, especialmente de outros países democráticos que adotam o regime parlamentarista, que o presidencialismo de coalizão brasileiro funciona de forma muito similar a outros modelos, o que inclusive explicaria sua estabilidade. Os autores enfatizam as ferramentas que a presidência da República possui para criar e manter a coalizão parlamentar e especialmente para garantir certo controle da agenda no Legislativo Federal. Esta abordagem pavimentou um arcabouço teórico que apontou para a direção da cooperação entre os poderes ao contrário do conflito distributivo das análises que indicavam a suposta correlação entre a liberação de emendas ao orçamento e o apoio parlamentar ao governo. Diante das suposições de que haveria uma conexão entre a preferência por emendas ao orçamento e uma fragilidade dos partidos no parlamento e nas arenas eleitorais (ocasionada pela suposição de que a negociação entre Executivo e Legislativo se daria de forma individualizada e pautada na barganha individual fisiológica entre Executivo e parlamentares), alguns estudos trataram de testar a hipótese (em nível federal) de que a liberação de emendas parlamentares por parte do Executivo condicionaria as votações de interesse do Governo no Congresso. Vasselai e Mignozzetti (2014) testam uma aproximação entre as execuções das emendas parlamentares pelo Executivo às preferências do governo entre 1996 e 2010. Após a análise, os autores dizem não ser possível sustentar a hipótese popularmente difundida.

Assim, outros mecanismos, que não a barganha individual com parlamentares, foram utilizados pelo Executivo para garantir apoio às suas pautas. Figueiredo e Limongi indicam que estes mecanismos decorrem, principalmente, da arquitetura institucional de nosso sistema político. O primeiro ponto decorre da força do Poder Executivo, que deriva de (a) prerrogativas exclusivas deste Poder para iniciar a tramitação de matérias orçamentárias; (b) possibilidade de editar Medidas Provisórias (MP's) que consequentemente incentivam a cooperação parlamentar na medida em que força o legislativo a votar a matéria uma vez findado o prazo de vigência da MP; e (c) possibilidade de tramitação em regime de urgência ou mesmo urgência urgentíssima caso a maioria parlamentar assim decida em votação. No tocante ao Poder Legislativo, dois aspectos centrais devem ser destacados: 1) a disciplina partidária dos membros da coalizão e 2) a

\footnotetext{
${ }^{4}$ Estes cálculos são feitos pelos autores através de simples divisões que originam razões. A divisão de "Número de projetos aprovados oriundos do Executivo" sobre "Número total de projetos aprovados pelo Congresso" indica a razão de dominância do Executivo sobre o Legislativo na medida em que indica a porcentagem de projetos aprovados que nascem no gabinete presidencial. Para o cálculo da taxa de sucesso do Executivo os autores dividem o "Número de projetos, oriundos no Executivo, transformados em Lei pelo Parlamento", pelo "total de projetos enviados ao Parlamento pelo Executivo".
} 
centralização decisória no Legislativo, expressa no Colégio de Líderes, que tem a faculdade de definir, junto com a presidência da Casa, a pauta de votações no plenário.

Os cálculos "Taxa de Sucesso" e "Taxa de Dominância" do Executivo utilizados por Figueiredo e Limongi foram e continuam a ser extensivamente reproduzidos quando o objetivo é analisar os padrões de interação entre os dois poderes supracitados. Os dados mais atualizados dos estudos de Figueiredo e Limongi encontram-se abaixo nos índices de Sucesso e Dominância do Poder Executivo Federal.

A observação dos dados organizados pelo Centro Brasileiro de Análise e Planejamento (CEBRAP) e que sustentam os trabalhos de Figueiredo e Limongi permitem que se verifique um elevado grau de sucesso do Executivo Federal. Este poder gozou de uma média de sucesso na casa dos $84 \%$ e uma dominância média de $88 \%$ sobre a agenda Legislativa. Note-se que estes valores são muito próximos aos valores apresentados pelos autores acerca da amostra de 20 países parlamentaristas observados entre 1971-1976 e 1978-1982. Nestes períodos indicados a taxa de dominância do Executivo em tais amostras foram de 86,4\% e 89,9\% respectivamente. Nota-se uma taxa de sucesso média na casa dos $84 \%$ durante o período. Os dados sobre a amostra de países parlamentaristas indicam para uma taxa de sucesso do executivo de 81,3\% (Figueiredo e Limongi, 2001, pp. 102). Cabe indicar que os cálculos de sucesso realizados pelo NECI consideram apenas os projetos de Lei aprovados dentro do mandato presidencial que enviou os respectivos projetos.

Tabela 1 - Taxa de Dominância e Sucesso do Executivo Federal em relação ao Legislativo Federal

\begin{tabular}{lll}
\hline Presidente & Sucesso & Dominância \\
\hline Sarney & & \\
\hline Collor & $87 \%$ & $89 \%$ \\
\hline Itamar & $76 \%$ & $94 \%$ \\
\hline FHC & $88 \%$ & $95 \%$ \\
\hline FHC II & $91 \%$ & $90 \%$ \\
\hline Lula & $83 \%$ & $88 \%$ \\
\hline Lula II & $89 \%$ & $88 \%$ \\
\hline Dilma & $87 \%$ & $80 \%$ \\
\hline Dilma II & $84 \%$ & $83 \%$ \\
\hline Temer & $90 \%$ & $83 \%$ \\
\hline médias & $62 \%$ & $89 \%$ \\
\hline
\end{tabular}

Fonte: Banco de Dados do Legislativo do CEBRAP. Elaboração: NECI (USP), 2021.

A verificação dos dados referentes à agenda parlamentar do Poder Executivo brasileiro 
durante a segunda experiência democrática confirma a hipótese da estabilidade do presidencialismo de coalizão, refutando, assim, os prognósticos pessimistas que supunham um potencial de conflito alto entre os poderes com possível paralisia decisória. Crises governamentais foram e continuam a ser atravessadas por muitos governos sem necessariamente implicarem na dissolução dos mesmos ou na incapacidade da solução de impasses entre os poderes.

Antes de tratarmos desse modelo de relações Executivo-Legislativo em nível municipal, é importante destacar que análises recentes têm revelado uma dinâmica nova e distinta no presidencialismo de coalizão brasileiro, na qual o Parlamento ganha maior projeção e proeminência frente ao presidente da República.

Araújo e Silva (2012) já apontavam para a importância dos parlamentares na formulação de políticas públicas por meio de uma análise menos binária sobre a atuação dos poderes nos projetos de lei que tramitam no Congresso. Para os autores, faz-se necessário observar o papel desempenhado pelos parlamentares no processo legislativo federal, mesmo em matérias de iniciativa do Executivo.

Na mesma linha, Freitas (2013) salienta que um dos aspectos institucionais apontados por Limongi e Figueiredo como variável explicativa da capacidade de controle da agenda legislativa pelo Executivo estaria superdimensionado. $\mathrm{O}$ argumento de que a possibilidade de a coalizão governamental solicitar que uma determinada matéria seja avaliada em regime de "urgência" ou de "urgência urgentíssima", e consequentemente seja votada em Plenário, retirando-a das comissões temáticas da casa, foi frequentemente apontado como uma das explicações da alta taxa de sucesso do Executivo. No entanto, Freitas indica que $45 \%$ dos projetos passíveis de tramitar em regime de urgência - PL's (Projetos de Lei Ordinária) e PLP's (Projetos de Lei Complementar) - aprovados entre 1988 e 2010 foram deliberados no interior de comissões antes de serem votados em Plenário.

Vê-se, assim, que o Parlamento brasileiro não age apenas como um ator passivo às demandas do Executivo. Os parlamentares desempenham papel ativo na apreciação do conteúdo das matérias, especialmente nas comissões nas quais os projetos tramitam. Trata-se da própria negociação que possibilita a obtenção de consensos acerca das matérias e posteriormente garante altos índices de disciplina observados em plenário (FREITAS, 2013, pp. 116), e demonstra que as aprovações de matérias oriundas do Executivo são resultado também de esforços dos parlamentares, principalmente dos relatores nas comissões.

Almeida (2015) arremata essa discussão com análise abrangente da produção legislativa recente da Câmara dos Deputados. Ao analisar as leis federais não orçamentárias (cuja iniciativa não é exclusiva do Poder Executivo), o autor aponta existir uma clara diminuição da atuação da Presidência nestas formulações. Até 2004, este tipo de matéria proveniente do Executivo correspondia a cerca de $60 \%$ do total das matérias não orçamentárias do Processo Legislativo; já a partir de 2008, este número cai pela metade do total de matérias não orçamentárias apresentadas 
(Almeida, 2015, pp. 46). A atuação do Parlamento neste tipo de Lei aumentou de 38,4\% para 80,9\% na comparação entre os períodos de 1995-2002 e 2007-2014.

Comparando os dois períodos supracitados, aponta-se para: (1) diminuição da quantidade de PL's aprovados em regime de urgência, que passam de 28,7\% para 13,8\%; e (2) aumento da quantidade de PL's aprovados de forma conclusiva nas comissões parlamentares, que passam de 9,8\% para $29,1 \%$ do total. Ao observar todos os tipos de projetos de lei com iniciativa do Congresso, a porcentagem de projetos que foram aprovados de forma conclusiva nas comissões passou de 52,9\% em 1995-2002 para 83,8\% em 2007-2014.

Nota-se, assim, que os estudos que analisam a produção legal nas relações entre Executivo e Legislativo no âmbito Federal têm evidenciado o aprofundamento do papel dos congressistas no processo legislativo. Se Freitas (2013) já havia observado a importância do papel das comissões parlamentares e o papel central dos relatores para garantir o consenso necessário para manter os altos índices de disciplina partidária no plenário, Almeida (2015) deu um passo adiante e revelou, ao atentar para o aumento da quantidade de matérias aprovadas de forma conclusiva e a diminuição dos projetos não orçamentários de origem no Poder Executivo, que a balança da força dos poderes Executivo e Legislativo parece estar se inclinando na direção deste último. Resta saber se e em que medida essa recomposição de forças afetará a capacidade de o presidente da República implementar sua agenda e a própria estabilidade do sistema político brasileiro.

\subsection{Estudos sobre a relação entre Executivo e Legislativo em São Paulo}

A carência de estudos que mirem a relação Executivo-Legislativo em nível municipal já seria estímulo suficiente para se inquirir se o "modus operandi" do presidencialismo de coalizão federal e seus resultados em termos de produção legislativa se aplica no âmbito municipal. $O$ quadro analítico e empírico exposto ao final da seção anterior sobre mudanças na relação de forças entre o presidente da República e o Congresso Nacional nos aponta, ademais, um caminho de investigação, no sentido de observar se o papel de destaque crescente angariado pelo Legislativo em nível federal se reflete no município de São Paulo.

Em estudo na década de 1990, Abrucio e Couto (1995) afirmam ser difícil replicar as análises da interação entre Legislativo e Executivo no contexto federal para as realidades municipais. As dificuldades encontradas pelo executivo federal em montar sua base de sustentação no Congresso não aparecem nas esferas municipais nem nas estaduais, pois nesses casos os legisladores não contam com fiadores políticos (governadores e senadores) dos quais dispõem os Deputados Federais. Além disso, seria necessário atentar-se para as diferenças encontradas no padrão de interação entre poderes nos municípios pequenos e médios com relação às capitais e grandes cidades, pois: "Se, por um lado, [nas capitais e grandes cidades] não há o ultrapresidencialismo, por outro, também não se configura uma situação na qual o parlamento tenha um grande poder de veto, tal qual o Congresso Nacional" (ABRUCIO; COUTO, 1995, p. 
$59)^{5}$. Abrucio e Couto ainda apontam para a existência de fatores exógenos às regras institucionais capazes de modular as práticas de governo, em São Paulo, tais quais: (i) a existência de estruturas administrativas regionais como principal moeda de troca (administrações regionais/subprefeituras); (ii) a existência de eventuais lideranças políticas no parlamento municipal; e, (iii) a opinião pública.

Em que pesem essas dificuldades analíticas, Issa e Oliveira (2017) buscaram analisar o processo legislativo no município de São Paulo entre 2008 e 2016 justamente sob a ótica da interação entre o Executivo e o Legislativo. Em forte contraste com o padrão federal, os dados encontrados pelos autores indicam que a maior parte dos projetos de lei aprovados neste período tiveram origem da vereança, evidenciando uma baixa taxa de domínio da agenda por parte do Executivo. Esta constatação não indica, porém, que o Executivo seja refém do Legislativo em São Paulo, haja vista que o Executivo goza de elevadas taxas de sucesso em suas proposituras enviadas à Câmara.

Conclusões preliminares dos autores apontam, assim, para a negação da tese de que os vereadores paulistanos não se preocupariam com a formulação de políticas públicas no município e trabalhariam apenas para a concessão de honrarias e alterações de nomes de ruas. Ao evidenciarem que o Executivo gozou de altas taxas de sucesso entre 2008 e 2016 ao mesmo tempo em que teve baixas taxas de dominância da produção legal, os autores ressaltam o ativismo do Poder Legislativo local ao mesmo tempo em que sugerem que este ativismo não se contrapõe às demandas do Poder Executivo.

Garcia (2013), ao estudar a produção legislativa em São Paulo entre Erundina e Kassab, afirma que o Plenário da Câmara Municipal de São Paulo é previsível na medida em que o Poder Executivo pôde aprovar praticamente todos os projetos de lei de sua iniciativa que foram à plenário, mesmo quando o Executivo não contava com uma coalizão maioritária (GARCIA, 2013, pp. 41).

Tais análises tornam-se, desta maneira, um importante ponto de partida para o presente estudo, na medida em que aplicaremos modelo similar, mas estendido a período mais amplo.

\section{Metodologia, Banco de dados e Hipótese}

Com o acesso a uma parte do Banco de Dados Legislativos do CEBRAP foi possível compreender como os cálculos de sucesso e dominância do poder Executivo são realizados pelos autores a fim de reproduzi-los para o nível municipal dentro de um espaço temporal delimitado.

Foi solicitado junto à Ouvidoria da Câmara Municipal de São Paulo, com base na Lei de Acesso à Informação (LAI), artigo $4^{\circ}$, inciso I, um banco de dados, observando-se a Lei Orgânica

\footnotetext{
${ }^{5}$ Ultrapresidencialismo será compreendido como a tática "rolo compressor", onde o Executivo tem garantida a maioria suficiente para aprovar quaisquer medidas no Legislativo.
} 
do Município (LOM) e o Regimento Interno da Câmara Municipal de São Paulo (RICM), com as seguintes características: listagem, por data de apresentação, de todos os I - projetos de emendas à LOM (PLO); II - projetos de leis (PL); III - projetos de decreto legislativo (PDL); IV - Projetos de Resolução (PR) apresentados à Câmara Municipal de São Paulo no período entre 26/04/1991 e 31/12/2016. Solicitou-se, ainda, que tal listagem contivesse a especificação do tipo de projeto apresentado, sua ementa, bem como sua origem (Legislativo, Executivo, Comissões Permanentes de Caráter Técnico-Legislativo, TCM). A última solicitação feita diz respeito ao status mais recente dos projetos: aprovado, sancionado, transitando em comissão, etc.

A base de dados obtida continha o proponente de cada um dos projetos apresentados, listando todos os projetos de lei apresentados entre 26/04/1991 e 31/12/2016. Dos 22.883 projetos listados, verificou-se que 7.316 deles haviam sido promulgados até 31/12/2016.

De todos os projetos apresentados durante este período, interessam especialmente aqueles que foram apresentados e promulgados dentro do mesmo período. Esta opção metodológica visa verificar, especialmente com relação aos projetos de competência concorrente ${ }^{6}$, a força (ou fraqueza) do Executivo na tramitação dos Projetos de seu interesse dentro do mandato. Essa opção, portanto, tem influência direta no resultado dos cálculos de dominância e sucesso do Executivo feitos neste trabalho.

Para facilitar a compreensão acerca da competência de apresentação de cada tipo de projeto, fez-se necessário um breve estudo da Lei Orgânica do Município de São Paulo (LOM) e do Regimento Interno da Câmara Municipal de São Paulo (RICM). Com esta breve análise, temos o quadro abaixo:

Quadro 1 - Tipos de projetos

\begin{tabular}{|l|c|c|}
\hline \multicolumn{1}{|c|}{ Tipos de Projetos } & Executivo pode enviar? & Legislativo pode enviar? \\
\hline Projetos de Emenda à Lei Orgânica (PLO) & SIM & SIM \\
\hline Projetos de Lei (PL) & SIM & SIM \\
\hline Projetos de Decreto Legislativo (PDL) & NÃO & SIM \\
\hline Projetos de Resoluções (PR) & NÃO & SIM \\
\hline
\end{tabular}

Fonte: O quadro foi elaborado através da análise dos artigos 234, 235, 236 e 237 do RICM de São Paulo, e, dos artigos 36, 37 e 137 da LOM de São Paulo.

Das análises propostas na próxima seção, indica-se atenção especial para os projetos de competência concorrente entre poderes (PL's e PLO's), visto que principalmente os PL's são as iniciativas que mais influem no dia-a-dia da cidade. Além disso, os Decretos e os Projetos de Resoluções respondem a funções administrativas da Câmara, com nenhuma relação com a

\footnotetext{
${ }^{6}$ Entende-se como competência concorrente aqueles projetos cuja apresentação pode ser feita tanto pelo Executivo quanto pelo Legislativo;
} 
atividade legislativa (MEIRELES, 1991, apud CAETANO, 2005, p. 109), uma vez que versam sobre a organização interna da CM e a distribuição de títulos e outras honrarias.

A hipótese principal a ser testada neste trabalho, após a revisão bibliográfica empenhada, pode ser descrita como:

H1: A relação Executivo-Legislativo no município de São Paulo entre 1991 e 2016 seguiu o padrão verificado no nível federal, com altas taxas de sucesso e dominância do Executivo sobre o Legislativo paulistano.

Para confirmar ou refutar tal hipótese, uma análise descritiva dos dados será apresentada na próxima seção através da análise de matérias que tramitaram na Câmara Municipal de São Paulo entre 1991 e 2016, focando-se especialmente as matérias de competência concorrente, apresentadas e promulgadas dentro de um mesmo mandato.

\section{Resultados e Discussão}

A partir do tratamento do Banco de Dados realizaram-se cálculos com o objetivo de se obter estatísticas descritivas a respeito do Processo Legislativo do Município de São Paulo durante o período mencionado.

A Tabela 2, apresentada abaixo, mostra o número total de matérias apresentadas e promulgadas independentemente da origem e também independentemente de ter sido aprovada dentro do mandato no qual foi proposta ou não. Do total de matérias apresentadas, 7.316 foram aprovadas, representando um $32 \%$ do total apresentado.

Tabela 2 - Total de matérias apresentadas e promulgadas independentemente da origem e da data de aprovação

\begin{tabular}{|l|c|c|c|c|c|c|c|c|}
\hline Governo & Erundina & Maluf & Pitta & Suplicy & $\begin{array}{c}\text { Serra } \\
\text { Kassab }\end{array}$ & Kassab & Haddad & Total \\
\hline $\begin{array}{l}\text { Total matérias } \\
\text { promulgadas }^{1}\end{array}$ & 267 & 1.322 & 999 & 1.231 & 1.312 & 1.165 & 1.020 & 7.316 \\
\hline $\begin{array}{l}\text { Total matérias } \\
\text { apresentadas }\end{array}$ & 1.031 & 4.598 & 3.586 & 3.577 & 3.695 & 3.043 & 3.353 & 22.883 \\
\hline $\begin{array}{l}\text { \% de matérias } \\
\text { promulgadas/total }\end{array}$ & $25,9 \%$ & $28,8 \%$ & $27,9 \%$ & $34,4 \%$ & $35,5 \%$ & $38,3 \%$ & $30,4 \%$ & $32,0 \%$ \\
\hline
\end{tabular}

Fonte: Banco de Dados da SGP-31 (CMSP). Elaboração própria.

A próxima tabela (Tabela 3) apresenta o total de matérias apresentadas e promulgadas 
dentro de cada governo, indicando ainda a porcentagem que estas matérias representam sobre o total de matérias promulgadas. Das 7.316 matérias promulgadas no período desta pesquisa, 5.564 foram apresentadas e promulgadas dentro de um mesmo mandato. É sob este número que posteriormente são feitos os cálculos de dominância e sucesso do executivo, haja vista a opção metodológica já mencionada anteriormente. A porcentagem de matérias que são apresentadas, independentemente do proponente, e promulgadas dentro do mesmo mandato, é alta e contesta crenças de que o Processo Legislativo seria pouco ágil e célere; $76,1 \%$ das matérias que são promulgadas na CM são aprovadas dentro de 4 anos. Pesquisas futuras podem avaliar os motivos que levam determinadas matérias a serem promulgadas com tamanha celeridade enquanto quantidade considerável das matérias apresentadas sequer são promulgadas mesmo no decorrer dos 25 anos analisados.

Tabela 3 - total de matérias promulgadas dentro de cada governo

\begin{tabular}{|l|c|c|c|c|c|c|c|c|}
\hline Governo & $\begin{array}{c}\text { Erundin } \\
\mathbf{a}\end{array}$ & $\begin{array}{c}\text { Malu } \\
\mathbf{f}\end{array}$ & Pitta & Suplicy & $\begin{array}{c}\text { Serra } \\
\text { Kassab }\end{array}$ & Kassab & $\begin{array}{c}\text { Hadda } \\
\text { d }\end{array}$ & Total \\
\hline $\begin{array}{l}\text { Total matérias } \\
\text { promulgadas dentro do } \\
\text { governo1 }\end{array}$ & 204 & 1.016 & 806 & 997 & 827 & 882 & 832 & $\mathbf{5 . 5 6 4}$ \\
\hline $\begin{array}{l}\text { Total matérias } \\
\text { promulgadas }\end{array}$ & 267 & 1.322 & 999 & 1.231 & 1.312 & 1.165 & 1.020 & 7.316 \\
\hline $\begin{array}{l}\text { \% de matérias } \\
\text { promulgadas dentro do } \\
\text { gov./total promulgadas }\end{array}$ & $76,4 \%$ & $76,9 \%$ & 80,7 & $81,0 \%$ & $63,0 \%$ & $75,7 \%$ & $81,6 \%$ & $76,1 \%$ \\
\hline
\end{tabular}

Fonte: Banco de Dados da SGP-31 (CMSP). Elaboração própria.

A próxima tabela (Tabela 4) busca identificar a porcentagem de matérias apresentadas e promulgadas dentro de um mesmo mandato sobre o total de matérias apresentadas durante cada mandato independentemente do tipo de proponente. Assim observa-se que aproximadamente 1/4 das matérias apresentadas durante o período analisado foi promulgada dentro de 4 anos. Esta informação aparentemente se contrapõe à informação anterior apresentada na Tabela 3. No entanto, conforme indicação anterior, enxerga-se que na realidade existe algum tipo de preferência de matérias capaz de fazer com que algumas matérias sejam apreciadas dentro de 4 anos enquanto outras simplesmente não sejam analisadas por completo ou tardem para serem analisadas. 
Tabela 4 - Total de Matérias apresentadas e promulgadas dentro de cada governo

\begin{tabular}{|c|c|c|c|c|c|c|c|c|}
\hline Governo & Erundina & Maluf & Pitta & Suplicy & $\begin{array}{c}\text { Serra } \\
\text { Kassab }\end{array}$ & $\begin{array}{c}\text { Kassa } \\
\text { b }\end{array}$ & Haddad & Total \\
\hline $\begin{array}{l}\text { Total matérias } \\
\text { promulgadas dentro do } \\
\text { governo }^{1}\end{array}$ & 204 & 1.016 & 806 & 997 & 827 & 882 & 832 & 5.564 \\
\hline $\begin{array}{l}\text { Total matérias } \\
\text { apresentadas }^{2}\end{array}$ & 1.031 & 4.598 & 3.586 & 3.577 & 3.695 & 3.043 & 3.353 & 22.883 \\
\hline $\begin{array}{l}\text { \% de matérias } \\
\text { promulgadas dentro do } \\
\text { gov./ } \\
\text { total materiais } \\
\text { apresentadas }\end{array}$ & $19,8 \%$ & $22,1 \%$ & $\begin{array}{c}22,5 \\
\%\end{array}$ & $27,9 \%$ & $22,4 \%$ & $29,0 \%$ & $24,8 \%$ & $24,3 \%$ \\
\hline
\end{tabular}

Fonte: Banco de Dados da SGP-31 (CMSP). Elaboração própria.

A Tabela 5 faz uma desagregação no movimento de compreensão destas diferenças. Do total de matérias promulgadas e apresentadas dentro de um mesmo governo, verifica-se quantas são Projetos de Lei (PL), Projetos de Emenda à Lei Orgânica (PLO), Projetos de Decreto Legislativo (PDL) e quantas são Projetos de Resoluções (PR). Nota-se neste momento que: (1) a grande maioria das matérias apresentadas são PL's - matérias de competência concorrente, conforme já indicado. Das 22.883 matérias apresentadas no período, 19.358 eram PL's; (2) Os PL's também representam a maior parte das matérias apresentadas e promulgadas dentro de um mesmo governo. Das 5.564 matérias apresentadas e promulgadas dentro de 4 anos, 3.818 eram PL's; 3) Os PLO's (outro tipo de matéria com competência concorrente entre os poderes) representam uma quantidade irrisória do total de matérias apresentadas e aprovadas. Das 22.883 matérias apresentadas no período, apenas 223 eram PLO's, e destas 223 matérias apresentadas, apenas 17 foram apresentadas e promulgadas dentro do mesmo mandato. De maneira geral, PLO's e PL's representam 85,5\% das matérias apresentadas na CM, sendo que os PL's sozinhos representam 84,5\% das matérias apresentadas. Das matérias apresentadas e promulgadas dentro de um mesmo governo, PLO's e PL's representam 68,9\% do total, sendo que PL's sozinhos representam $68,6 \%$. 
Tabela 5 - Matérias promulgadas dentro de cada Governo por tipo, independentemente de origem

\begin{tabular}{|c|c|c|c|c|c|c|c|c|}
\hline Governo & Erundina & Maluf & Pitta & Suplicy & $\begin{array}{c}\text { Serra } \\
\text { Kassab }\end{array}$ & Kassab & Haddad & Total \\
\hline $\begin{array}{l}\text { Total matérias } \\
\text { promulgadas } \\
\text { dentro do gov. }{ }^{1}\end{array}$ & 204 & 1.016 & 806 & 997 & 827 & 882 & 832 & 5.564 \\
\hline PL & 146 & 824 & 594 & 636 & 456 & 523 & 639 & 3.818 \\
\hline PDL & 46 & 149 & 183 & 318 & 354 & 328 & 167 & 1.545 \\
\hline PR & 11 & 40 & 29 & 38 & 13 & 27 & 26 & 184 \\
\hline PLO & 1 & 3 & & 5 & 4 & 4 & 0 & 17 \\
\hline $\begin{array}{l}\text { Total matérias } \\
\text { apresentadas }^{2}\end{array}$ & 1.031 & 4.598 & 3.586 & 3.577 & 3.695 & 3.043 & 3.353 & 22.883 \\
\hline PL & 827 & 4.040 & 3.090 & 2.970 & 3.096 & 2.508 & 2.827 & 19.358 \\
\hline PDL & 139 & 424 & 373 & 384 & 460 & 405 & 415 & 2.600 \\
\hline PR & 47 & 95 & 101 & 172 & 111 & 87 & 89 & 702 \\
\hline PLO & 18 & 39 & 22 & 51 & 28 & 43 & 22 & 223 \\
\hline $\begin{array}{l}\text { \% de matérias } \\
\text { promulgadas } \\
\text { dentro do } \\
\text { gov./total }\end{array}$ & $19,8 \%$ & $22,1 \%$ & $22,5 \%$ & $27,9 \%$ & $22,4 \%$ & $29,0 \%$ & $24,8 \%$ & $24,3 \%$ \\
\hline PL & $17,7 \%$ & $20,4 \%$ & $19,2 \%$ & $21,4 \%$ & $14,7 \%$ & $20,9 \%$ & $22,6 \%$ & $19,7 \%$ \\
\hline PDL & $33,1 \%$ & $35,1 \%$ & $49,1 \%$ & $82,8 \%$ & $77,0 \%$ & $81,0 \%$ & $40,2 \%$ & $59,4 \%$ \\
\hline PR & $23,4 \%$ & $42,1 \%$ & $28,7 \%$ & $22,1 \%$ & $11,7 \%$ & $31,0 \%$ & $29,2 \%$ & $26,2 \%$ \\
\hline PLO & $5,6 \%$ & $7,7 \%$ & $0,0 \%$ & $9,8 \%$ & $14,3 \%$ & $9,3 \%$ & $0,0 \%$ & $7,6 \%$ \\
\hline
\end{tabular}

Fonte: Banco de Dados da SGP-31 (CMSP). Elaboração própria.

A tabela seguinte (Tabela 6) inicia as análises sobre dominância e sucesso do Executivo sobre o Legislativo. Verificam-se nela as porcentagens do total de matérias promulgadas dentro de cada governo sobre o total apresentado, separando a origem das matérias entre Executivo e Legislativo. Nota-se neste momento que a maior parte das matérias apresentadas tem origem no Legislativo. Das 22.883 matérias apresentadas durante o período, 21.219 tiveram origem no Legislativo. No entanto, a taxa de sucesso do Executivo é muito superior à taxa de sucesso do Legislativo. Enquanto o primeiro aprova $47,1 \%$ das suas matérias dentro de 4 anos, o segundo aprova $22,5 \%$ das matérias que propõe dentro de 4 anos. Ao analisarmos de forma destacada as taxas de sucesso dos executivos petistas, notamos claras diferenças, que sugerem serem atribuídas aos métodos adotados na negociação parlamentar de cada um dos governos. Erundina teve apenas $27 \%$ de seus projetos aprovados, enquanto Suplicy aprovou 62,6\% dos projetos que enviou, e Haddad aprovou 64,9\%. Em todas as administrações, no entanto, percebe-se um sucesso muito 
maior do Executivo do que do Legislativo nas suas respectivas agendas parlamentares.

Tabela 6 - Taxa de Sucesso do Executivo e Legislativo em matérias apresentadas e aprovadas dentro do mandato

\begin{tabular}{|c|c|c|c|c|c|c|c|c|}
\hline Governo & Erundina & Maluf & Pitta & Suplicy & $\begin{array}{c}\text { Serra } \\
\text { Kassab }\end{array}$ & Kassab & $\begin{array}{c}\text { Hadda } \\
\text { d }\end{array}$ & Total \\
\hline $\begin{array}{l}\text { Total matérias } \\
\text { promulgadas } \\
\text { dentro do gov. }\end{array}$ & 204 & 1.016 & 806 & 997 & 1.520 & 882 & 832 & 5.564 \\
\hline $\begin{array}{l}\text { Com origem no } \\
\text { Executivo }\end{array}$ & 58 & 201 & 53 & 199 & 75 & 99 & 98 & 783 \\
\hline $\begin{array}{l}\text { Com origem no } \\
\text { Legislativo }\end{array}$ & 146 & 815 & 753 & 798 & 752 & 783 & 734 & 4.781 \\
\hline $\begin{array}{l}\text { Total matérias } \\
\text { apresentadas }\end{array}$ & 1.031 & 4.598 & 3.586 & 3.577 & 6.131 & 3.043 & 3.353 & 22.883 \\
\hline $\begin{array}{l}\text { Com origem no } \\
\text { Executivo }\end{array}$ & 215 & 442 & 208 & 318 & 162 & 168 & 151 & 1.664 \\
\hline $\begin{array}{l}\text { Com origem no } \\
\text { Legislativo }\end{array}$ & 816 & 4.156 & 3.378 & 3.259 & 3.533 & 2.875 & 3.202 & 21.219 \\
\hline Taxa de sucesso & $19,8 \%$ & $22,1 \%$ & $22,5 \%$ & $27,9 \%$ & $24,8 \%$ & $29,0 \%$ & $24,8 \%$ & $24,3 \%$ \\
\hline do Executivo & $27,0 \%$ & $45,5 \%$ & $25,5 \%$ & $62,6 \%$ & $46,3 \%$ & $58,9 \%$ & $64,9 \%$ & $47,1 \%$ \\
\hline do Legislativo & $17,9 \%$ & $19,6 \%$ & $22,3 \%$ & $24,5 \%$ & $21,3 \%$ & $27,2 \%$ & $22,9 \%$ & $22,5 \%$ \\
\hline
\end{tabular}

Fonte: Banco de Dados da SGP-31 (CMSP). Elaboração própria.

A seguinte tabela (Tabela 7) apresenta os dados de dominância do Executivo sobre o Legislativo levando-se em consideração: (1) apenas as matérias apresentadas e promulgadas dentro de um mesmo mandato e (2) apenas as matérias de competência concorrente entre os poderes. Erundina e Marta dominaram mais o Legislativo do que Haddad, por exemplo. À exceção da administração de Pitta, pode-se destacar um movimento de diminuição da dominância do Poder Executivo na produção legislativa durante os anos. Do total de 3.835 matérias apresentadas e promulgadas dentro de 4 anos que possuíam competência concorrente, cerca de $20 \%$ tinham origem no Executivo apenas. Apenas 3 das 17 PLO's apresentadas e promulgadas dentro de 4 anos foram apresentadas pelo Executivo. Nota-se em todos os casos um baixo número de PLO's apresentados. Conclui-se, portanto, que a relação entre os poderes está fundada basicamente em PL's no que se refere ao Processo Legislativo do Município. A Taxa de dominância do Executivo representa a taxa de dominância geral do Executivo sobre o Processo Legislativo. 
Tabela 7 - Taxas de Dominância do Executivo apenas para matérias promulgadas dentro dos mandatos

\begin{tabular}{|c|c|c|c|c|c|c|c|c|}
\hline Governo & Erundina & Maluf & Pitta & Suplicy & $\begin{array}{c}\text { Serra } \\
\text { Kassab }\end{array}$ & Kassab & Haddad & Total \\
\hline $\begin{array}{l}\text { Total promulgado dentro } \\
\text { gov. (Executivo + } \\
\text { Legislativo) }\end{array}$ & 147 & 827 & 594 & 641 & 460 & 527 & 639 & 3.835 \\
\hline PL & 146 & 824 & 594 & 636 & 456 & 523 & 639 & 3.818 \\
\hline PLO & 1 & 3 & 0 & 5 & 4 & 4 & 0 & 17 \\
\hline $\begin{array}{l}\text { Total promulgado dentro } \\
\text { gov. (Legislativo) }\end{array}$ & 89 & 626 & 541 & 442 & 385 & 428 & 541 & 3.052 \\
\hline PL & 88 & 624 & 541 & 438 & 381 & 425 & 541 & 3.038 \\
\hline PLO & 1 & 2 & 0 & 4 & 4 & 3 & 0 & 14 \\
\hline $\begin{array}{l}\text { Total promulgado dentro } \\
\text { gov. (Executivo) }\end{array}$ & 58 & 201 & 53 & 199 & 75 & 99 & 98 & 783 \\
\hline PL & 58 & 200 & 53 & 198 & 75 & 98 & 98 & 780 \\
\hline PLO & 0 & 1 & 0 & 1 & 0 & 1 & 0 & 3 \\
\hline $\begin{array}{l}\text { Taxa de dominância do } \\
\text { Executivo }\end{array}$ & $39,5 \%$ & $24,3 \%$ & $8,9 \%$ & $31,0 \%$ & $16,3 \%$ & $18,8 \%$ & $15,3 \%$ & $20,4 \%$ \\
\hline PL & $39,7 \%$ & $24,3 \%$ & $8,9 \%$ & $31,1 \%$ & $16,4 \%$ & $18,7 \%$ & $15,3 \%$ & $20,4 \%$ \\
\hline PLO & $0,0 \%$ & $33,3 \%$ & & $20,0 \%$ & $0,0 \%$ & $25,0 \%$ & & $17,6 \%$ \\
\hline
\end{tabular}

Fonte: Banco de Dados da SGP-31 (CMSP). Elaboração própria.

A tabela seguinte (Tabela 8) apresenta a taxa de sucesso do executivo, contando apenas as matérias promulgadas dentro do governo, em PL's e PLO's. Neste momento identificam-se aqueles governos com maiores taxas de sucesso em suas investidas no Parlamento: Haddad, Suplicy e Kassab. Por outro lado, Pitta e Erundina apresentam as menores taxas de sucesso. 

maior compartilhamento de poder?

Tabela 8 - Taxa de Sucesso do Poder Executivo

\begin{tabular}{|l|c|c|c|c|c|c|c|c|}
\hline Governo & Erundina & Maluf & Pitta & $\begin{array}{c}\text { Suplic } \\
\mathbf{y}\end{array}$ & $\begin{array}{c}\text { Serra } \\
\text { Kassab }\end{array}$ & $\begin{array}{c}\text { Kassa } \\
\text { b }\end{array}$ & $\begin{array}{c}\text { Hadda } \\
\text { d }\end{array}$ & Total \\
\hline $\begin{array}{l}\text { Total matérias } \\
\text { promulgadas dentro do } \\
\text { gov. c/ origem } \\
\begin{array}{l}\text { Executivo } \\
\text { Total matérias }\end{array}\end{array}$ & 201 & 53 & 199 & 75 & 99 & 98 & 783 \\
\hline $\begin{array}{l}\text { apresentadas pelo } \\
\text { Executivo }\end{array}$ & 215 & 442 & 208 & 318 & 162 & 168 & 151 & 1.664 \\
\hline $\begin{array}{l}\text { Taxa de sucesso do } \\
\text { Executivo }\end{array}$ & $\mathbf{2 7 , 0 \%}$ & $\mathbf{4 5 , 5 \%}$ & $\mathbf{2 5 , 5 \%}$ & $\mathbf{6 2 , 6 \%}$ & $\mathbf{4 6 , 3 \%}$ & $\mathbf{5 8 , 9 \%}$ & $\mathbf{6 4 , 9 \%}$ & $\mathbf{4 7 , 1 \%}$ \\
\hline
\end{tabular}

Fonte: Banco de Dados da SGP-31 (CMSP). Elaboração própria.

A próxima tabela (Tabela 9) apresenta a taxa de sucesso do executivo, contando apenas as matérias promulgadas dentro do governo desagregadas em PL e PLO. A maior parte das matérias enviadas pelo Executivo ao Processo Legislativo são PL's. Das 1.664 matérias enviadas pelo Executivo, 1.656 eram PL's, e das 783 matérias enviadas pelo Executivo que foram aprovadas dentro do mandato, 780 eram PL's. O Executivo manteve uma taxa de sucesso de suas matérias na casa de 47,1\%. Haddad e Suplicy apresentaram as maiores taxas de sucesso: 64,9\% e $62,6 \%$ respectivamente.

Tabela 9 - Taxa de sucesso do executivo para matérias promulgadas dentro do governo desagregadas em PL e PLO

\begin{tabular}{|l|c|c|c|c|c|c|c|c|}
\hline Governo & Erundina & Maluf & Pitta & $\begin{array}{c}\text { Suplic } \\
\mathbf{y}\end{array}$ & $\begin{array}{c}\text { Serra } \\
\text { Kassab }\end{array}$ & Kassab & $\begin{array}{c}\text { Hadda } \\
\mathbf{d}\end{array}$ & Total \\
\hline $\begin{array}{l}\text { Total promulgado } \\
\text { dentro gov. } \\
\text { (origem no } \\
\text { executivo) }\end{array}$ & $\mathbf{5 8}$ & $\mathbf{2 0 1}$ & $\mathbf{5 3}$ & $\mathbf{1 9 9}$ & $\mathbf{7 5}$ & $\mathbf{9 9}$ & $\mathbf{9 8}$ & $\mathbf{7 8 3}$ \\
\hline $\begin{array}{l}\text { PL } \\
\text { PLO }\end{array}$ & 58 & 200 & 53 & 198 & 75 & 98 & 98 & 780 \\
\hline
\end{tabular}




\begin{tabular}{|l|c|c|c|c|c|c|c|c|}
\hline $\begin{array}{l}\text { enviadas (origem } \\
\text { no executivo) }\end{array}$ & 215 & 441 & 208 & 315 & 162 & 167 & 148 & 1.656 \\
\hline PL & 0 & 1 & 0 & 3 & 0 & 1 & 3 & 8 \\
\hline PLO & $\mathbf{2 7 , 0 \%}$ & $\mathbf{4 5 , 5 \%}$ & $\mathbf{2 5 , 5 \%}$ & $\mathbf{6 2 , 6 \%}$ & $\mathbf{4 6 , 3 \%}$ & $\mathbf{5 8 , 9 \%}$ & $\mathbf{6 4 , 9 \%}$ & $\mathbf{4 7 , 1 \%}$ \\
\hline $\begin{array}{l}\text { Taxa de sucesso } \\
\text { do Executivo }\end{array}$ & $27,0 \%$ & $45,4 \%$ & $25,5 \%$ & $62,9 \%$ & $46,3 \%$ & $58,7 \%$ & $\mathbf{6 6 , 2 \%}$ & $47,1 \%$ \\
\hline PL & & $100,0 \%$ & & $33,3 \%$ & & $100,0 \%$ & $0,0 \%$ & $37,5 \%$ \\
\hline
\end{tabular}

Fonte: Banco de Dados da SGP-31 (CMSP). Elaboração própria.

A última tabela (Tabela 10), a seguir, busca contrapor os resultados de dominância e sucesso do Executivo entre as duas esferas governamentais mencionadas ao decorrer deste trabalho, Federal e Municipal.

Tabela 10 - Taxa de Dominância e Sucesso do Executivo Federal e do Executivo de São Paulo

\begin{tabular}{|c|c|c|c|c|c|}
\hline Presidente & Sucesso & Dominância & Prefeito & Sucesso & Dominância \\
\hline Collor & $76 \%$ & $94 \%$ & Erundina & $27 \%$ & $40 \%$ \\
\hline Itamar & $88 \%$ & $95 \%$ & Maluf & $46 \%$ & $24 \%$ \\
\hline FHC & $91 \%$ & $90 \%$ & Pitta & $26 \%$ & $9 \%$ \\
\hline FHC II & $83 \%$ & $88 \%$ & Suplicy & $63 \%$ & $31 \%$ \\
\hline Lula & $89 \%$ & $88 \%$ & $\begin{array}{c}\text { Serra } \\
\text { Kassab }\end{array}$ & $46 \%$ & $16 \%$ \\
\hline Lula II & $87 \%$ & $80 \%$ & Kassab & $59 \%$ & $19 \%$ \\
\hline Dilma & $84 \%$ & $83 \%$ & Haddad & $65 \%$ & $15 \%$ \\
\hline Dilma II & $90 \%$ & $83 \%$ & & & \\
\hline Temer & $62 \%$ & $89 \%$ & & & \\
\hline médias & $75 \%$ & $79 \%$ & médias & $47 \%$ & $20 \%$ \\
\hline
\end{tabular}

Fonte: Banco de Dados do Legislativo do CEBRAP e Banco de Dados da SGP-31 (CMSP). Elaboração própria

O Executivo Municipal, apesar de gozar de prerrogativas legais tão importantes quanto o Executivo Federal, tais quais competência exclusiva para iniciar determinados tipos de matérias, poder de veto, possibilidade de solicitar urgência na apreciação de projetos, prover cargos e funções públicas, não desempenha uma coordenação legislativa tão afinada quanto seu irmão maior. Nenhum dos prefeitos paulistanos entre 1991 e 2016 alcançou uma taxa de sucesso 
próxima à média de sucesso do Executivo Federal. O prefeito que obteve melhor desempenho foi Haddad com $65 \%$ de suas matérias enviadas sendo aprovadas dentro do seu próprio mandato. Mais discrepante ainda é a taxa de dominância do processo legislativo municipal pelo Executivo, fato que sugere uma maior cooperação entre os poderes ou mesmo maior protagonismo do Legislativo - embora este fato, como evidenciam Issa e Oliveira (2017), não representa necessariamente uma contraposição às demandas do Executivo.

\section{Conclusão}

Os esforços empreendidos na execução deste trabalho orientaram-se na direção de proporcionar uma visão ampla da interação entre Executivo e Legislativo no município de São Paulo (no que se refere estritamente à produção legal) durante um intervalo temporal relativamente grande se comparado com as pesquisas anteriores que focalizaram poucas administrações do período. A aplicação de taxas de sucesso e dominância do Poder Executivo no Processo Legislativo permitiu não apenas comparações entre as distintas administrações do município como também entre o município e a União.

Os resultados encontrados são muito interessantes e nos provocam algumas reflexões. Em primeiro lugar, seguindo o padrão federal, o Executivo paulistano possui uma taxa de sucesso na aprovação de suas matérias muito superior, mais que o dobro, na comparação com o Poder Legislativo. Isso mostra que o Executivo, frente a um Legislativo fragmentado em termos partidários, tem muito mais condições de levar adiante sua agenda a partir da coalizão construída.

De todo modo, salta aos olhos a diferença entre as taxas de sucesso nas duas esferas federativas. A taxa de sucesso em nível federal alcança 75\%, enquanto em São Paulo o percentual não atinge 50\%. Em outras palavras, é dizer que o presidente da República implementa $3 / 4$ de sua agenda, enquanto o prefeito de São Paulo não reúne as condições de levar adiante nem metade de sua plataforma política. Esses dados causam surpresa, pois era esperado que o prefeito tivesse maior facilidade de implementação de sua agenda. Não como nos municípios menores, onde impera o ultrapresidencialismo, mas certamente com maior facilidade do que o presidente da República, que precisa lidar com um Congresso Nacional muito mais complexo, formado por duas casas, e com grau de fragmentação partidária mais intenso. Nesse sentido, fica refutada parcialmente a hipótese do artigo em sua primeira dimensão. Ou seja, as taxas de sucesso do Executivo não são baixas nem menores que as do Legislativo, mas tampouco são altas, destoando do padrão federal.

Em relação à taxa de dominância, encontramos um resultado ainda mais inesperado e discrepante em relação à esfera federal. Enquanto nesta esfera o Executivo domina a produção legal, alcançando, na média histórica, quase $80 \%$ do total de leis aprovadas, o Executivo municipal apresenta não apenas um valor inferior, mas um valor extremamente baixo, de $20 \%$, o que torna a Câmara Municipal o poder dominante na produção legal. Esses dados sugerem que a 
dinâmica de poder entre os Poderes Executivo e Legislativo, ao menos no âmbito municipal paulistano, difere da esfera federal, revestindo-se de um caráter mais compartilhado, ou até favorável ao Legislativo, de sorte que os vereadores em São Paulo têm condições muito maiores de fazer avançar sua agenda paralelamente ao chefe do Executivo municipal. Os dados refutam peremptoriamente a segunda dimensão da hipótese apresentada e apontam para um jogo político mais equilibrado, que demanda maiores estudos para a plena compreensão. Vale destacar que as tendências verificadas por Almeida (2015) na esfera federal vão na mesma linha, embora em menor grau, ou seja, de um fortalecimento do Legislativo frente ao Executivo.

Projetando futuras análises sobre o tema, cabe fazer alguns apontamentos. O primeiro é avaliar o tipo de lei de que se trata. Isto porque são muitas as leis orçamentárias aprovadas em nível federal, o que não parece ocorrer em outras esferas. Da mesma forma, é importante observar se as leis municipais se referem, principalmente, a homenagens e condecorações, o que poderia explicar a força do Legislativo municipal na produção legal. A partir daí, estudos qualitativos poderiam trazer mais elementos para compreendermos melhor essa dinâmica de poder mais compartilhado observada no presente estudo. Isso será fundamental, pois os dados reunidos revelaram um padrão de interação Executivo-Legislativo completamente diferente do que seria esperado. Da dinâmica fortemente centralizada no Executivo encontrada em âmbito federal e do ultrapresidencialismo verificados nos municípios menores, passamos para o outro extremo do pêndulo, em que o Legislativo tem um papel preponderante na produção legal de São Paulo. Assim, apenas novas análises poderão revelar se as gritantes diferenças encontradas referem-se mais ao tipo de dado analisado ou estamos diante, de fato, de um novo padrão de interação Executivo-Legislativo.

\section{Agradecimentos}

Versões preliminares deste trabalho foram apresentadas no IX Seminário Discente do Programa de Pós-Graduação em Ciência Política da USP (2019) e na Semana de Ciência Política UFSCar/UFABC - Instituições Políticas, Políticas Públicas \& Cidadania (2019). Os autores agradecem os comentários recebidos nas duas ocasiões por colegas e professores, em especial agradecemos pelos comentários de Jonathan Phillips (USP), Lucio Rennó (UnB), Gleidylucy Oliveira (UFSCar), Simone Diniz (UFSCar) e Vinícius Alves (UFSCar). Este trabalho contou com o apoio do Departamento de Ciência Política da USP por meio do CAPES/PROEX.

\section{Referências}

ABRANCHES, S. (1988). Presidencialismo de Coalizão: o dilema institucional brasileiro.

Dados - Revista de Ciências Sociais, Rio de Janeiro, v. 31, n. 1, p. 5-34.

ABRUCIO, F. L; Couto, C. G. (1995). Governando a cidade? A força e a fraqueza da Câmara Municipal. São Paulo em Perspectiva. São Paulo, v. 9, n. 2, p. 57-65. 
ALMEIDA, A. (2015). Processo Legislativo: mudanças recentes e desafios. Boletim de Análise Político-Institucional, n. 7, Instituto de Pesquisas Econômicas Aplicadas (IPEA), jan-jul.

BRASIL. Câmara dos Deputados. Ato das Disposições Constitucionais Transitórias de 1988. Disponível em: http://www2.camara.leg.br/legin/fed/conadc/1988/constituicao.adct-1988-5outubro-1988-322234-publicacaooriginal-1-pl.html Acesso em: 15/10/2018

BRASIL. Câmara dos Deputados: Centro de Documentação e Informação. Regimento Interno da Câmara dos Deputados. Disponível em: http://www2.camara.leg.br/atividadelegislativa/legislacao/regimento-interno-da-camara-dosdeputados/RICD\%20atualizado\%20ate\%20RCD\%2027-2018.pdf. Acesso em: 5 de junho de 2018

FIGUEIREDO, A; LIMONGI, F. Poder de agenda, disciplina partidária e apoio partidário na Câmara dos Deputados. IN: FIGUEIREDO, A; LIMONGI, F. Executivo e Legislativo na nova ordem constitucional. $2^{\mathrm{a}}$ edição. Rio de Janeiro: Editora da FG, 2001, p.101-123

FREITAS, A. O presidencialismo da Coalizão. Tese de Doutorado. Universidade de São Paulo, capítulo 3, p. 108-116, 2013

GARCIA, J. G. Executivo e Legislativo no âmbito municipal: a formação de Gabinetes no Município de São Paulo (1989-2012). Dissertação de Mestrado. Fundação Getúlio Vargas, 2013, capítulo 5, p. 39-43, 2013

ISSA, M; OLIVEIRA, V. Cooperação, iniciativa e controle no processo legislativo municipal de São Paulo entre 2008 e 2016. IN: Poder Legislativo sob múltiplos olhares. Cadernos

Adenauer, Rio de Janeiro, ano 18, n. 2, p. 143-159, 2017

ARAÚJO, S. M. V. G.; e SILVA, R. S. Reflexões e Novas Agendas de Pesquisa pra os Estudos Legislativos no Brasil. RIEL - Revista Ibero-Americana de Estudos Legislativos, Rio de Janeiro, n. 2, outubro, 2012

VASSELAI, F.; MIGNOZZETI, U. G. O Efeito das Emendas ao Orçamento no Comportamento Parlamentar e a Dimensão Temporal: Velhas Teses, Novos Testes. Dados [online], vol.57, n.3, pp.817-853, 2014

SÃO PAUlO. Lei Orgânica do Município de São Paulo. Disponível em: http://www.prefeitura.sp.gov.br/cidade/secretarias/upload/educacao/cme/LOM.pdf. Acesso em: 1 de junho de 2018

SÃO PAULO. Câmara Municipal de São Paulo. Regimento Interno da Câmara Municipal de São Paulo. Disponível em: http://www.saopaulo.sp.leg.br/wpcontent/uploads/2018/01/RC291C.pdf. Acesso em: 1 de junho de 2018

\section{BANCOS DE DADOS UTILIZADOS}

Banco de Dados do Legislativo do CEBRAP

Banco de Dados da Equipe de Documentação do Legislativo - SGP-31 (CMSP)

Artigo submetido em: 2021-05-30;

Artigo aceito em: 2021-06-29 